\title{
Effects of vitamin E and selenium (Selevit) on the orchidectomized rats
}

\author{
Seung-Ki Chon* \\ Hyu Animal Clinic, Iksan 570-973, Korea
}

(Received 13 November 2010, accepted in revised from 22 March 2011)

\section{Abstract}

The present study was devised to determine the effects of body weight, organ weight, hematological values and biochemical parameters by vitamin $\mathrm{E}$ and selenium (Selevit) on the Orch rats. The animals were divided into 4 groups. Intact group $(n=10)$ received no treatment and operation. Sham group $(\mathrm{n}=10)$ received only sham operation and no treatment. Orch group received operation and no treatment. Orch + Selevit received operation and Selevit. The body weights of each group increased, but that of the Orch + Selevit group were significantly lower than those of all the other groups. There were significant differences $(P<0.001)$ of body weights between Orch + Selevit group and all the other groups. Also, organ weights such as heart, liver, spleen and kidney were measured. The heart weights were significantly lower $(P<0.001)$ in the Orch + Selevit group than in Intact and Sham group. The liver weights in the Orch + Selevit group were significantly differences $(P<0.001)$ in comparison with those in the Intact and Sham groups. The kidney weights in the Orch + Selevit group were significantly differences $(P<0.01, P<0.001)$ in comparison with those in all the other groups. On the other hand, there were no significantly differences in the organ weights of spleen between the Orch+ Selevit groups and the any other groups. The number of white blood cell (WBC) was significantly higher $(P<0.05)$ in the Orch + Selevit group than in all the other groups. The hematological values of red blood cell $(\mathrm{RBC})$, mean corpuscular volume (MCV), mean corpuscular hemoglobin $(\mathrm{MCH})$ and mean corpuscular hemoglobin concentration (MCHC) were not significantly different in any of the groups. The concentrations of serum total protein, albumin and alkaline phosphatase increased significantly $(P<0.05, P<0.01)$ in the Orch + Selevit group as compared to that in the Orch group. However, there were no significant differences in AST and ALT in any other groups. We conclude that Selevit was significantly decreased the body weight in the orchidectomized rats. Our findings suggest that Selevit may influence the process of lipid packaging and absorption in the orchidectomized rats.

Key words : Rat, Vitamin E and selenium (Selevit), Orchidectomized

\section{INTRODUCTION}

Vitamin $\mathrm{E}$ occurs in eight natural forms as tocopherols (alpha, beta, gamma, and delta) and tocotrienols (alpha, beta, gamma, and delta), all of which possess potent antioxidant properties. Gamma tocopherol is the predominant form of vitamin $\mathrm{E}$ in the human diet, yet most studies have focused on alpha tocopherol, which is the type found in most over the counter supplements.

*Corresponding author: Seung-Ki Chon, Tel. +82-63-831-5115,

Fax.+82-63-831-5115, E-mail. seungkichon@hanmail.net
One reason for this is that alpha tocopherol is biologically more active than gamma tocopherol. Vitamin E deficiency is rare and is seen primarily in special situations resulting in fat malabsorption, including cystic fibrosis, chronic cholestatic liver disease, abetalipoproteinemia, and short bowel syndrome (Thomas, 2006). Vitamin $\mathrm{E}$ is a major lipid soluble antioxidant and is an essential nutrient for normal growth and development. Its deficiency results in neurological dysfunction, muscular weakness, and reproductive failure (Burton et al, 1990; Kayden, 2001; Sies et al, 1992). 
Selenium is a common trace element in alkaline soils that enters the food chain via wheat, corn, and other forage plants. Following the discovery of selenium during the early 1800 s in the sediment of a swedish sulfuric acid plant, the mineral was considered for decades to be extremely toxic to animals at high levels and a possible carcinogen. By the late 1950s, however, scientists had concluded otherwise. They found that selenium is actually an essential component of the human diet that is necessary for growth and fertility. Selenium is essential at small amounts, but can be toxic in larger amounts. Humans and animals require selenium for the function of a number of selenium dependent enzymes, also known as selenoprotiens (Schwarz and Foltz, 1999; Longtin, 2003). Selenium supplements can be in 2 forms, inorganic or organic forms. Inorganic and organic forms of dietary selenium supplements are metabolized differently (Katzen-Luchenta, 2007). Selenomethionine is actively transported through intestinal membranes during the absorption process and non specifically incorporated into tissue proteins in place of methionine during protein synthesis (Schrauzer, 2003). In contrast, inorganic selenium is absorbed via passive diffusion and little is retained in tissue reserves. Consequently, a large proportion of inorganic selenium is excreted in the feces and urine (Combs, 2005).

Vitamin E and selenium are two well known antioxidative nutrients. Vitamin $\mathrm{E}$ is the most effective chain breaking lipid soluble antioxidant in the biological membrane. Both vitamin E and selenium are important in host antioxidant defense and immune function. Vitamin E is a lipid-soluble antioxidant present in cellular membranes that quenches free radicals and prevents lipid peroxidation (Esterbauer et al, 1991), and it is found in especially high concentrations in immune cells (Coquette et al, 1986). Vitamin E deficiency has been associated with increased oxidative stress (Awad et al, 1994) and impaired immune function including both humoral and cell mediated immunity, phagocyte function, and lymphocyte proliferation(Moriguchi and Muraga, 2000). Selenium is important for cytotoxic T lymphocyte and natural killer cell activity (KiremidjianSchumacher et al, 1994) and for protection against en- dotoxin-induced oxidative stress (Sakaguchi et al, 2000). Selenium supplementation suppresses TNF- $\alpha$ induced HIV replication in culture (Hori et al, 1997) and selenium deficiency can alter chemokine and cytokine expression in viral infections (Beck and Matthews, 2000). The present study was conducted to investigate whether Selevit is effective in changing the body weight, organ weight, hematological values and biochemical parameters in orchidectomized (Orch) rats.

\section{MATERIALS AND METHODS}

\section{Animals and diets}

Male Sprague-Dawley rats, aged 63 days, were purchased from Bio-Safety Research, Chonbuk National University and used for the experiment described below when they were 70 days old. The rats weighing 362 $414 \mathrm{~g}$ were placed in stainless steel wire bottomed plastic cages and housed in a room maintained at $23 \pm 1^{\circ} \mathrm{C}$ and humidity $55 \%$ on $12 \mathrm{hrs}$ light/dark cycles. All rats were allowed free access to a pelleted commercial diet and drinking water. After 1 week of acclimation, Rats were randomly assigned to 4 groups with 10 rats in each group. Orchidectomy was performed in the Orch and Orch + Selevit groups, animals in the Sham group were subjected to sham operation. Intact group had no operation nor treatment. The Orch + Selevit group was given the Selevit subcutaneously (Vitamin E Acetate, 70 $\mathrm{mg} / \mathrm{ml}$, Sodium selenite, $0.5 \mathrm{mg} / \mathrm{ml}$, Fatro) $280 \mathrm{mg} / \mathrm{kg}$ of vitamin $\mathrm{E}$ acetate and $2 \mathrm{mg} / \mathrm{kg}$ of sodium selenite for body weight for 3 times per week from 1 week after surgery.

\section{Orchidectomy}

After intraperitoneal anesthesia using ketamine (80 $\mathrm{mg} / \mathrm{kg}$ ) and xylazine $(10 \mathrm{mg} / \mathrm{kg})$, a midline scrotal incision was made. Testis was surgically resected. Specifically, both spermatic cords were ligated at the level of the upper part of the scrotum and the intact testis was removed. The scrotums of rats, sham group, 
were opened and the testis was exposed. The testis was then replaced in the scrotum and the wound was closed.

\section{Sample preparation}

The rats were weighted 2 times per week. After 5 weeks of treatment, the rats were killed under anesthesia, blood was collected from the vena cava into heparinized or nonheparinized tubes for hematological values (Scil Vet $\mathrm{abc}^{\mathrm{TM}}$, ABX Diagnostics, France) and biological parameters (Spotchem EZ ${ }^{\mathrm{TM}}$ SP-4430, ARKRAY, Japan). After blood collection to measure the organ weights, heart, liver, spleen and kidney were removed and stored in saline and then weighted.

\section{Statistical analysis}

All values were reported as mean and standard deviation (SD). Significant differences between the values were statistically analyzed using a one-way analysis of variance (ANOVA), followed by a two pairs Student's $t$ test. $P<0.05$ or less was considered statistically significant.

\section{RESULTS}

\section{Effect of vitamin $E$ and selenium (Selevit) on body weights}

Table 1 shows the effect of body weights on testis removed rats with Selevit administration. All rats increased body weights by the end of the experiment. Intact $(376.5 \pm 6.81 \mathrm{~g})$ and Orch + Selevit group (385.0 \pm $21.40 \mathrm{~g}$ ) had similar mean body weights at the start of the study. On the other hand, the weights of Sham
$(404.1 \pm 13.39 \mathrm{~g})$ and Orch $(400.1 \pm 15.76 \mathrm{~g})$ groups were slightly higher than those in the Intact and Orch+ Selevit groups, respectively. The body weights of Intact,

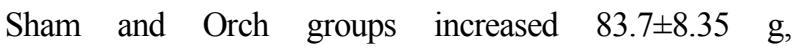
$58.1 \pm 22.84 \mathrm{~g}$ and $42.2 \pm 23.71 \mathrm{~g}$, respectively, whereas it only increased $15.7 \pm 10.85 \mathrm{~g}$ in the Orch + Selevit group. Selevit prevented the Orch-induced weight gain. The final body weights of Intact $(460.2 \pm 7.26 \mathrm{~g})$, Sham $(462.2 \pm 31.79 \mathrm{~g})$ and Orch groups $(442.3 \pm 23.81 \mathrm{~g})$ were significantly higher $(P<0.001)$ than that of the Orch + Selevit group $(400.7 \pm 21.53 \mathrm{~g})$.

\section{Effect of vitamin $E$ and selenium(Selevit) on organ weights}

The organ weights such as heart, liver, spleen and kidney were weighted and are shown in Table 2. The organ weights of the heart and liver in the Orch+ Selevit group $(1.2 \pm 0.06 \mathrm{~g}, \quad 13.2 \pm 0.52 \mathrm{~g})$ were significantly lower than those in the Intact $(1.5 \pm 0.09 \mathrm{~g}$, $15.2 \pm 0.48 \mathrm{~g})$ and Sham groups $(1.6 \pm 0.04 \mathrm{~g}, 15.6 \pm 0.66$ g), respectively. There were statistically significant differences $(P<0.001)$ for these organ weights between Orch + Selevit group and Intact and Sham group. Also, the kidneys of the Orch + Selevit group $(2.8 \pm 0.13 \mathrm{~g})$

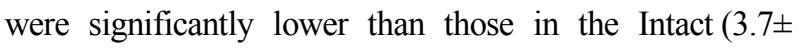
$0.35 \mathrm{~g})$, Sham $(3.7 \pm 0.21 \mathrm{~g})$ and $\operatorname{Orch}(3.4 \pm 0.41 \mathrm{~g})$ groups, respectively. There were statistically significant differences $(P<0.01, P<0.001)$ for these organ weights in the Intact, Sham and Orch group when compared with those of the Orch + Selevit group. However, the spleens of the Orch + Selevit group $(0.7 \pm 0.05 \mathrm{~g})$ were lower than those in the Intact $(0.8 \pm 0.04 \mathrm{~g})$, Sham group $(0.8 \pm 0.05 \mathrm{~g})$ and $\operatorname{Orch}(0.7 \pm 0.06 \mathrm{~g})$. There were no stat-

Table 1. Effects of vitamin E and selenium (Selevit) on body weight (BW) of orchidectomized rats

\begin{tabular}{lrrrc}
\hline & Intact & \multicolumn{1}{c}{ Sham } & Orch & Orch + Selevit \\
\hline Initial BW (g) & $376.5 \pm 6.81$ & $404.1 \pm 13.39$ & $400.1 \pm 15.76$ & $385.0 \pm 21.40$ \\
After 5 weeks BW (g) & $460.2 \pm 7.26$ & $462.2 \pm 31.79$ & $442.3 \pm 23.81$ & $400.7 \pm 21.53^{\text {c,f,l }}$ \\
BW gain/loss (g) & $83.7 \pm 8.35$ & $58.1 \pm 22.84$ & $42.2 \pm 23.71$ & $15.7 \pm 10.85$ \\
\hline
\end{tabular}

Changes in body weight treated with vitamin $\mathrm{E}$ and selenium (Selevit) on orchidectomized rats. These data in Intact (non-operated), Sham (Sham-operated), Orch (orchidectomized), Orch + Selevit (treated with Selevit on orchidectomized) are shown. ${ }^{\mathrm{c}, \mathrm{fl}}$ Indicate the significant differences in values after 5 weeks of Orch + Selevit vs. Intact, Sham and Orch, respectively. Data are mean \pm standard deviation. ${ }^{c} \mathrm{P}<0.001$ vs. Intact, ${ }^{\mathrm{f}} \mathrm{P}<0.001$ vs. Sham, ${ }^{\mathrm{l}} \mathrm{P}<0.001$ vs. Orch. 
Table 2. Effects of vitamin $\mathrm{E}$ and selenium (Selevit) on organ weight of orchidectomized rats

\begin{tabular}{lrrrc}
\hline & \multicolumn{1}{c}{ Intact } & \multicolumn{1}{c}{ Sham } & Orch & Orch + Selevit \\
\hline Heart $(\mathrm{g})$ & $1.5 \pm 0.09$ & $1.6 \pm 0.04$ & $1.2 \pm 0.31$ & $1.2 \pm 0.06^{\mathrm{c}, \mathrm{f}}$ \\
Liver $(\mathrm{g})$ & $15.2 \pm 0.48$ & $15.6 \pm 0.66$ & $13.3 \pm 0.55$ & $13.2 \pm 0.52^{\mathrm{c}, \mathrm{f}}$ \\
Spleen $(\mathrm{g})$ & $0.8 \pm 0.04$ & $0.8 \pm 0.05$ & $0.7 \pm 0.06$ & $0.7 \pm 0.05$ \\
Kidney $(\mathrm{g})$ & $3.7 \pm 0.35$ & $3.7 \pm 0.21$ & $3.4 \pm 0.41$ & $2.8 \pm 0.13^{\text {c.f.k }}$ \\
\hline
\end{tabular}

Changes in organ wet weight treated with vitamin $\mathrm{E}$ and selenium (Selevit) on orchidectomized rats. These data in Intact (non-operated),

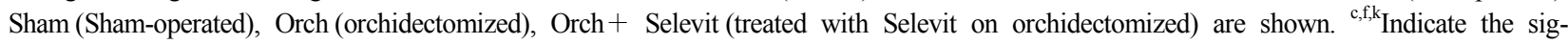
nificant differences in values after 5 weeks of Orch + Selevit vs. Intact, Sham and Orch, respectively. Data are mean \pm standard deviation. ${ }^{\mathrm{c}} P<0.001$ vs. Intact, ${ }^{\mathrm{f}} P<0.001$ vs. Sham, ${ }^{\mathrm{k}} P<0.01$ vs. Orch.

Table 3. Effects of vitamin $\mathrm{E}$ and selenium (Selevit) on hematological values of orchidectomized rats

\begin{tabular}{lrrrr}
\hline & \multicolumn{1}{c}{ Intact } & \multicolumn{1}{c}{ Sham } & Orch & Orch + Selevit \\
\hline WBC $\left(10^{3} / \mathrm{mm}^{3}\right)$ & $8.2 \pm 0.33$ & $8.2 \pm 0.26$ & $8.3 \pm 0.25$ & $8.7 \pm 0.48^{\mathrm{a}, \mathrm{d}, \mathrm{j}}$ \\
RBC $\left(10^{6} / \mathrm{mm}^{3}\right)$ & $7.9 \pm 0.29$ & $7.9 \pm 0.34$ & $7.8 \pm 0.23$ & $8.0 \pm 0.21$ \\
MCV $(\mu \mathrm{m} 3)$ & $54.9 \pm 1.10$ & $55.1 \pm 1.19$ & $56.2 \pm 2.20$ & $55.6 \pm 1.83$ \\
MCH $(\mathrm{pg})$ & $19.0 \pm 0.45$ & $19.1 \pm 0.51$ & $18.7 \pm 0.83$ & $19.0 \pm 0.71$ \\
MCHC $(\mathrm{g} / \mathrm{dl})$ & $35.0 \pm 0.65$ & $35.1 \pm 1.39$ & $33.9 \pm 1.67$ & $34.3 \pm 1.03$ \\
\hline
\end{tabular}

Changes in hematological values treated with vitamin $\mathrm{E}$ and selenium (Selevit) on orchidectomized rats. These data in Intact (non-operated), Sham (Sham-operated), Orch (orchidectomized), Orch + Selevit (treated with Selevit on orchidectomized) are shown. ${ }^{\mathrm{a}, \mathrm{dj}}$ Indicate the significant differences in values after 5 weeks of Orch + Selevit vs. Intact, Sham and Orch, respectively. Data are mean \pm standard deviation. ${ }^{\mathrm{a}} P<0.05$ vs. Intact, ${ }^{\mathrm{d}} P<0.05$ vs. Sham, ${ }^{\mathrm{j}} P<0.05$ vs. Orch.

Table 4. Effects of vitamin $\mathrm{E}$ and selenium (Selevit) on hematological values of orchidectomized rats

\begin{tabular}{lcccc}
\hline & Intact & Sham & Orch & Orch + Selevit \\
\hline T-pro (g/dl) & $6.7 \pm 0.13$ & $6.6 \pm 0.11$ & $6.5 \pm 0.16$ & $6.7 \pm 0.11^{\mathrm{g}}$ \\
Alb (g/dl) & $5.2 \pm 0.09$ & $5.2 \pm 0.13$ & $5.0 \pm 0.15$ & $5.2 \pm 0.28^{\mathrm{g}}$ \\
Alp (IU/l) & $429.1 \pm 18.02$ & $430.0 \pm 13.66$ & $410.3 \pm 14.95$ & $433.6 \pm 18.38^{\mathrm{h}}$ \\
AST (IU/l) & $99.5 \pm 20.56$ & $100.0 \pm 18.84$ & $99.1 \pm 15.70$ & $100.5 \pm 15.37$ \\
ALT (IU/l) & $54.2 \pm 3.82$ & $54.0 \pm 3.94$ & $53.6 \pm 4.11$ & $55.3 \pm 3.46$ \\
\hline
\end{tabular}

Changes in biochemical parameters treated with vitamin $\mathrm{E}$ and selenium (Selevit) on orchidectomized rats. These data in Intact (non-operated), Sham (Sham-operated), Orch (orchidectomized), Orch + Selevit (treated with Selevit on orchidectomized) are shown. ${ }^{\text {g.h }}$ Indicate the significant differences in values after 5 weeks of Orch + Selevit vs. Orch. Data are mean \pm standard deviation. ${ }^{\mathrm{g}} P<0.05$ vs. Orch, ${ }^{\mathrm{h}} P$ $<0.01$ vs. Orch.

istically significant differences for these organ weights in any other groups.

\section{Effect of vitamin $E$ and selenium(Selevit) on hematological values}

The hematological values are shown in Table 3. The numbers of WBC were significantly higher $(P<0.05)$ in the Orch + Selevit group $\left(8.7 \pm 0.4810^{3 /} \mathrm{mm}^{3}\right)$ than those in the Intact group $\left(8.2 \pm 0.3310^{3 /} \mathrm{mm}^{3}\right)$, Sham group $\left(8.2 \pm 0.2610^{3} / \mathrm{mm}^{3}\right)$ and Orch group $\left(8.3 \pm 0.2510^{3} / \mathrm{mm}^{3}\right)$, respectively. However, there was no statistically sig- nificant difference in RBC among groups. Additionally, there was no statistically significant difference for the levels of MCV, MCH and MCHC between the groups. The hematological values except the numbers of WBC have not significantly influenced by the Selevit administration.

\section{Effect of vitamin E and selenium(Selevit) on biochemical parameters}

The serum concentrations of total protein (T-pro), albumin (Alb), alkaline phosphatase (Alp), aspartate ami- 
notransferase (AST) and alanine aminotransferase (ALT) are shown in Table 4. The levels of T-pro and Alb were significantly $(P<0.05)$ increased in the Orch + Selevit group $(6.7 \pm 0.11 \mathrm{~g} / \mathrm{dl}, 5.2 \pm 0.28 \mathrm{~g} / \mathrm{dl})$ when compared with those of the Orch group $(6.5 \pm 0.16 \mathrm{~g} / \mathrm{dl}$, $5.0 \pm 0.15 \mathrm{~g} / \mathrm{dl})$, respectively. However, in the Intact and Sham group, the levels of T-pro $(6.7 \pm 0.13 \mathrm{~g} / \mathrm{dl}, 6.6 \pm 0.11$ $\mathrm{g} / \mathrm{dl})$ and $\mathrm{Alb}(5.2 \pm 0.09 \mathrm{~g} / \mathrm{dl}, 5.2 \pm 0.13 \mathrm{~g} / \mathrm{dl})$ were moderately increased as compared to that of the Orch + Selevit group, but this increase was not significant. The levels of Alp, in the Orch + Selevit group $(433.6 \pm 18.38 \mathrm{IU} / 1)$, were significantly $(P<0.01)$ increased compared to those of the Orch group $(410.3 \pm 14.95 \mathrm{IU} / \mathrm{l})$. On the other hand, the levels of AST and ALT were slightly increased in the Sham $(100.0 \pm 18.84 \mathrm{IU} / 1,54.0 \pm 3.94 \mathrm{IU} / \mathrm{l})$ and Orch + Selevit $(100.5 \pm 15.37$ IU/1, $55.3 \pm 3.46 \mathrm{IU} / \mathrm{l})$ group when compared with those of the Intact $(99.5 \pm$ $20.56 \mathrm{IU} / 1,54.2 \pm 3.82 \mathrm{IU} / 1)$ and $\operatorname{Orch}(99.1 \pm 15.70 \mathrm{IU} / 1$, $53.6 \pm 4.11 \mathrm{IU} / 1)$ group, but there were not statistically significant differences between the groups, respectively.

\section{DISCUSSION}

The main purpose of this study was to evaluate whether vitamin $\mathrm{E}$ and selenium (Selevit) changes body weight, organ weight, hematological values and biochemical parameters induced by orchidectomized rats. Our data on the Orch +Selevit group support the observations of other investigators that body weight gain due to orchidectomy is prevented by vitamin $\mathrm{E}$ and selenium (Selevit). These observations are supported by recent observations of Al Shamsi et al (2004), who reported that vitamin E significantly reduced blood glucose levels in experimental diabetes mellitus at all doses as compared to untreated rats. Vitamin $\mathrm{E}$ induced weight loss in normal as well as in diabetic rats. The beneficial effect of vitamin $\mathrm{E}$ on the hyperglycaemia of diabetic rats was dose-dependent. Moreover, vitamin E also improved the oral glucose tolerance test in diabetic rats compared to untreated diabetics. Finally, Al Shamsi et al (2004) speculate that vitamin E may play a role in glucose metabolism and thus be a useful adjuvant ther- apy in type I diabetes.

With respect to organ weights except spleens, animals in the Orch + Selevit group had significantly lower organ weights than rats in the Intact, Sham and Orch groups. This lower organ weight gain was due to vitamin $\mathrm{E}$ and selenium, despite similar food consumption. Because lipid accumulation in the liver was inhibited by vitamin $\mathrm{E}$ administration, vitamin $\mathrm{E}$ play a role in lipoprotein synthesis and the transportation of lipids, and may possibly inhibit the deactivation of metabolic enzymes. This finding is consistent with the view that antioxidants can play an important role in the treatment of obesity-related diseases (Schrauzer, 2003).

Contrary to the expectation, vitamin $\mathrm{E}$ and selenium (Selevit) in Orch + Selevit animals significantly increased serum concentrations of one of the biochemical parameters, Alp, compared with the concentrations in Orch animals. This may suggest that vitamin $\mathrm{E}$ and selenium (Selevit) does not inhibit bone turnover as does $17 \beta$ estradiol. Further studies are needed to clarify whether this protective effect on bone is due to the enzymes itself or to the presence of vitamin E and/or selenium, such as antioxidants.

Additionally, Yachi et al (2010) demonstrated that the content of triglycerides in the liver was increased by administration of carbon tetrachloride, but the increase was significantly suppressed by the administration of vitamin E. On the other hand, there were no significant differences in liver total cholesterol content among the groups. AST activity in plasma was increased by administration of carbon tetrachloride, but this was unaffected by administration of vitamin E analogs. On the other hand, ALT activity also tended to increase after administration of carbon tetrachloride. However, the rise in the plasma ALT level tended to be suppressed by gamma tocopherol administration, and vitamin $\mathrm{E}$ had a significant suppressive effect. However, our data on biochemical parameters, the serum concentrations of AST and ALT increased in Orch + Selevit animals compared with concentrations in Intact, Sham and Orch animals. Although we have no definitive explanations as to why this occurs, we speculate that vitamin $\mathrm{E}$ and selenium, which acts antioxidants, might serve as a source of scavenger. 


\section{REFERENCES}

Al Shamsi MS, Amin A, Adeghate E. 2004. Beneficial effect of vitamin $\mathrm{E}$ on the metabolic parameters of diabetic rats. Mol Cell Biochem 261(1-2): 35-42.

Awad JA, Morrow JD, Hill KE, Roberts LJ 2nd, Burk RF. 1994. Detection and localization of lipid peroxidation in selenium and vitamin E-deficient rats using F2-isoprostanes. J Nutr 124(6): 810-816.

Beck MA, Matthews CC. 2000. Micronutrients and host resistance to viral infection. Proc Nutr Soc 59(4): 581-585.

Burton GW, Ingold KU, Cheeseman KH, Slater TF. 1990. Application of deuterated alpha-tocopherols to the biokinetics and bioavailability of vitamin E. Free Radic Res Commun 11(1-3): 99-107.

Combs GF Jr. 2005. Current evidence and research needs to support a health claim for selenium and cancer prevention. J Nutr 135(2): 343-347.

Coquette A, Vray B, Vanderpas J. 1986. Role of vitamin E in the protection of the resident macrophage membrane against oxidative damage. Arch Int Physiol Biochim 94(5): 2934.

Esterbauer H, Dieber-Rotheneder M, Striegl G, Waeg G. 1991. Role of vitamin $\mathrm{E}$ in preventing the oxidation of low-density lipoprotein. Am J Clin Nutr 53(1S): 314S$321 \mathrm{~S}$.

Hori K, Hatfield D, Maldarelli F, Lee BJ, Clouse KA. 1997. Selenium supplementation suppresses tumor necrosis factor alpha-induced human immunodeficiency virus type 1 replication in vitro. AIDS Res Hum Retroviruses 13(15): $1325-1332$.

Katzen-Luchenta J. 2007. The declaration of nutrition, health, and intelligence for the child-to-be. Nutr Health 19(1-2):
85-102.

Kayden HJ. 2001. The genetic basis of vitamin E deficiency in humans. Nutrition 17(10): 797-798.

Kiremidjian-Schumacher L, Roy M, Wishe HI, Cohen MW, Stotzky G. 1994. Supplementation with selenium and human immune cell functions. II. Effect on cytotoxic lymphocytes and natural killer cells. Biol Trace Elem Res 41(1-2): 115-127.

Longtin R. 2003. Selenium for prevention: eating your way to better DNA repair? J Natl Cancer Inst 95(2): 98-100.

Moriguchi S, Muraga M. 2000. Vitamin E and immunity. Vitam Horm 59: 305-336.

Sakaguchi S, Iizuka Y, Furusawa S, Tanaka Y, Takayanagi M, Takayanagi Y. 2000. Roles of selenium in endotoxin-induced lipid peroxidation in the rats liver and in nitric oxide production in J774A. 1 cells. Toxicol Lett 118(1-2): 69-77.

Schrauzer GN. 2003. The nutritional significance, metabolism and toxicology of selenomethionine. Adv Food Nutr Res 47: 73-112.

Schwarz K, Foltz CM. 1999. Selenium as an integral part of factor 3 against dietary necrotic liver degeneration. Nutrition 15(3): 255.

Sies H, Stahl W, Sundquist AR. 1992. Antioxidant functions of vitamins. Vitamins $\mathrm{E}$ and $\mathrm{C}$, beta-carotene, and other carotenoids. Ann N Y Acad Sci 669: 7-20.

Thomas DR. 2006. Vitamins in aging, health, and longevity. Clin Interv Aging 1(1): 81-91.

Yachi R, Igarashi O, Kiyose C. 2010. Protective Effects of Vitamin E Analogs against Carbon TetrachlorideInduced Fatty Liver in Rats. J Clin Biochem Nutr 47(2): 148-154. 